\title{
Audit Recognition to Falsified Methods in Financial Statements of Listed Companies in China
}

\author{
Chuanlian Song \\ School of Economics \& Management, Changchun University of Science and Technology \\ Changchun 130022, China \\ E-mail: chuanliansong@163.com
}

\begin{abstract}
Falsified financial statements have already become an international and historic issue. How to judge and audit the falsified activities in financial statements has been the focus of accounting research, and also the major problems deserving governments to solve. In recent years, the management level of enterprises in China falsifies financial statements by all methods to conceal the real financial conditions, business operations, and cash flows, with different aims. As a result, it causes great losses to the state. Besides, information users can not make the right decision with these falsified financial statements, causing a serious credit mess in market. This paper analyzes the motives of enterprises in China for falsifying financial statements, and also the common methods, advancing relevant methods for auditing recognition.
\end{abstract}

Keywords: Financial statements, Falsified methods, Audit recognition

\section{Introduction}

In China, listing in stock market and financing through the stock market is the cost-lowest way for enterprises collecting capitals. Because of special economic environment, many stock enterprises are founded on state-owned companies. Some state-owned companies make falsified financial statements and assets evaluations in order to get the approvals of China Securities Regulatory Commission. Otherwise, they are not qualified in issuing stocks openly in market. After listing in market, some enterprises in losses may choose to make up or release false accounting information by adding virtual profits and reducing real looses, cheating investors, in order to acquire more funds by issuing more stocks at higher prices. Not only enterprises prefer to make false, local government even support their illegal activities. To found stock companies can collect considerable funds to develop local economy and improve their performances. With support from local government, other problems can be solved easily. Revealing the falsified methods in accounting statements used by listed enterprises in China and performing the audit recognition are meaningful for regulating the accounting market, driving the long-term development of investment market, and protecting the interests of small and medium investors.

\section{Common falsified methods in financial statements}

\subsection{Cheating by related transactions}

China has always emphasized on relations. Although the accounting principles regulate the accounting treatments between related parties and the auditing principles regulate the auditing recognition of related parties in transaction, the management level can conceal the relations or turn explicit relations into implicit ones under present system due to the implicit feature of relations in order to avoid supervision.

A typical approach is to perform related transactions based on internal group structure. Then, the profits can be controlled well. For example, the parent company purchases products or services from holding subsidiaries at premium prices and forms its fixed assets. Then, the holding subsidiaries' return can be recognized as the current consolidated statement profits. Or, the parent company sells products to holding shareholders and non-holding subsidiaries. Then, the sales will rise and so do the accounts receivable and profits. The parent company sells products or services to the third party at the market price and confirms the sales of subsidiaries. Then, another subsidiary purchases the products or services from the third party. By this way, it avoids the constraints of related transactions between parent company and subsidiaries, ensuring the income and profits in consolidated statements, and achieving the goal of controlling profits. In addition, it is common to falsify the return by false contracts in related transactions.

\subsection{Cheating by assets reorganization}

In order to strengthen enterprises' competitiveness, optimize the distribution of resources, and gain more profits, the reorganization of assets is an effective way. But in fact, many listed companies in China perform assets reorganization not for improving the competitiveness, but taking it as a method to falsify financial statements, in order to collecting more funds from capital market. In these cheating activities, the most common way is to 
perform the reorganization by assets replacement. On one hand, the parent company gets rid of all or part of bad assets by agreements and the big shareholder or group invests in more good assets, which changes the company's assets structure thoroughly. Or the company exchanges their bad assets with the good assets of parent company or other company, changing the company's financial conditions, and reducing the proportion of bad assets. On the other hand, the company transfers their assets at premium prices and improves its current income. In the reorganization of assets, the premium-price transfer is the convenient way to improve the company's current return, especially if the holding company is powerful. The company sells the assets to its holding company at premium prices, which can make it get higher income.

\subsection{Adjusting the return and profit indexes in every accounting period}

The popular way to control profits is to adjust the return and profits indexes in every accounting period. If the products need to be equipped or after-sale services and the sale periods are long, the return is not realized at once. Especially for trans-yearly sales, the profits must be distributed in the year. Then, the company may choose to transfer or delay the costs in accounts before the sales have been done. By this way, it can adjust profits effectively.

\subsection{Adjusting profits by falsifying virtual transactions}

In accounting, enterprises may improve profits by falsifying virtual transactions. For example, Fengle Seed has false records since its listing in market in April, 1997. In ten years from 1997 to 2007, Fengle Seed falsified 191 million Yuan income. At the same time, it writes off the main business income of 11 million Yuan. In accumulation, it falsifies the main business cost of 22 million Yuan. And the virtual main business income is 180 million Yuan. And the falsified main business profits are 158 million Yuan. Besides, Fengle Seed turns the return from securities and relevant allowances into main business income and relevant accounts receivable. However, its real return from securities is lower than falsified main business profits in every year. Thus, the balance forms the virtual profits of each year. The accumulated virtual profits reach 40.06 million Yuan, etc.

\subsection{Cheating by improper accounting policies and accounting evaluation}

The management may choose improper accounting policies and evaluations to control profits. For one transaction, the company can choose different accounting treatments. And China's specific accounting principles do not concern every aspect of corporate accounting. Therefore, many listed companies can control profits and falsify financial statements by choosing or changing accounting policies and accounting evaluations. For example, Yutaibai turned a loan of 86.04 million Yuan into a project in construction in 2006. But in fact, this project had begun in 2005. And in 2006 there were qualified products already. By this way, it makes the profits rise by more than 80 million Yuan.

\section{The auditing recognition to falsified methods in financial statements}

\subsection{Identifying the related parties and related transactions}

In general, the listed company in China is supported by a giant group. Similar to a big family, there are complex relations between child companies, brother companies, and parent company. As the managers face financial pressures, they may adopt the related transactions. For this kind of transaction, there are only in form but not in practice. Sometimes, the prices and conditions for payment are special. In hard time, it is easy to find that two parties can not fulfill the transaction considering their real financial conditions. Enron Corporation lists falsified profits, which are realized mostly by related transactions. All these facts make it more difficult for CPA finding related parties and their transactions. Therefore, the CPA must know the ownership relations of listed company, question more on abnormal transactions, check conference records carefully, consult the management agency with strategies, and study more cases concerning related transactions. By this way, the CPA can be more capable of finding related transactions.

Considering potential related transactions, we should investigate these issues: (1) whether there is a fixed process for the management level, by which the CPA can recognize related parties and related transactions; (2) whether there are sufficient information to know and evaluate the relations of two parties in transaction; (3) whether the two parties have motives or abilities to execute the transaction; (4) whether the accounting treatment is based on the essence of transactions (including any abnormal condition); (5) whether relevant information, such as the transaction nature, contents, and relations, is released completely.

\subsection{Analyzing the reorganization of assets}

Under the fierce market competition, some enterprises may be in loss or weak in winning profits due to bad management, and harmful influences from external elements. Capitals flow slowly. In this condition, the enterprise may reach an agreement with creditors to get rid of all or part of bad assets, or exchange the bad assets with the good assets of the parent company or the shell company, in order to change the financial conditions, 
reducing the proportion of bad assets. If an enterprise changes its assets structure significantly, the auditors should pay more attention to the necessity and reasonability of changes. If an enterprise performs assets reorganization or transfer in a report period, the auditors should focus on the impacts of assets reorganization or transfer on the enterprise. By analyzing its necessity, reasonability, and legality, the auditors can judge whether the enterprise adjusts profits or avoids taxes by assets reorganization and assets transfer. If an enterprise invests in other fields, gets mortgage loans, and commute debts by its assets in a report period, the auditors should notice the balance between relevant assets' evaluation values and accounting values. By analyzing its necessity and reasonability, the auditors can judge whether the enterprise adjusts the value of assets by assets evaluation.

\subsection{Checking on trans-period incomes especially}

For the balance sheet, the management level usually takes the profits in current year as the profits in next year or the profits in next year as the profits in current year. For example, in Nov. 2008, the global financial crisis happened. Most enterprises were in loss in Nov. 2008. In order to make monthly profits in balance, the management level usually adjusts the part of profits in Jan. 2009 to the year 2008, balancing the profits in every month in 2008, and increasing the profits virtually. In contrast, if profits in certain year are sufficient, the management level may adjust profits in last month in this year to the first month in next year, balancing the profits, which can help the enterprise to win more investors. Considering these conditions, the auditors should focus on major abnormal trans-period transactions, check the sales voices and relevant bills, ensuring that whether certain income is reflected in the balance sheet.

\subsection{Analyzing the abnormal profits}

Sometimes, the managers want to beautify the business performances or achieve the expected goal by convincible sales. The auditors should be careful on abnormal or irregular transactions. Contracts or terms are not so convincible. They must check all items by their special senses. For example, as for a potential irregular transaction, no matter whether the sum is large or not, the auditors should check on the original documents and consult for creditors and debtors to testify the completeness of the transaction. Besides, we should pay special attentions to possible agreements outside the contract. If an enterprise's main income is from other business income, investments, or non-business income, the auditors should care about the authenticity of transaction, judging whether the enterprise cheats or not.

\subsection{Focusing on whether accounting policies and evaluations are in accordance with accounting principles}

Accounting policies are specific rules in accounting check and accounting treatments adopted by enterprises. Whether accounting policies are proper or not is vital for the enterprise's accounting treatments, or even whether the accounting profits can be calculated properly or not. In common, the listed company can control profits and falsify business performances by choosing or changing accounting policies and evaluations.

\section{Conclusion}

The falsified financial statements seriously disturb normal social economic activities, influencing investors' analysis and estimations on kinds of economic information, misleading the investors, creditors, and relevant decision-makers. As a result, the financial statements of listed company and relevant auditing reports are lack of pre-warning effects, adding more audit risks, hurting China's capital market, and disturbing normal social economic orders.

In a word, financial statements users should recognize and defend against listed companies' illegal activities concerning financial statements, narrowing the space for falsified methods by accounting principles and relevant regulations, and ensuring the normal development of whole social and economic orders.

\section{References}

$\mathrm{Tu}$, Chuanfen. (2007). How to defend frauds in financial statements. Auditing \& Finance in Jiangxi. No.9.

Wang, Huacheng \& Jiang, Shuncai. (2007). Information asymmetry and CPA's credit construction. China Certificate Public Accountant. No.8.

Huang, Peng. (2006). Game analysis of listed companies' fraudulent financial statements. China Certificate Public Accountant. No.11.

Zhang, Limin \& Chen, Xiaolin. (2007). Reason analysis of fraudulent financial statements. China Certificate Public Accountant. No. 8.

Li, Xuefen. (2008). Measures for recognizing and defending fraudulent financial statements. Commercial Accounting. No.2. 